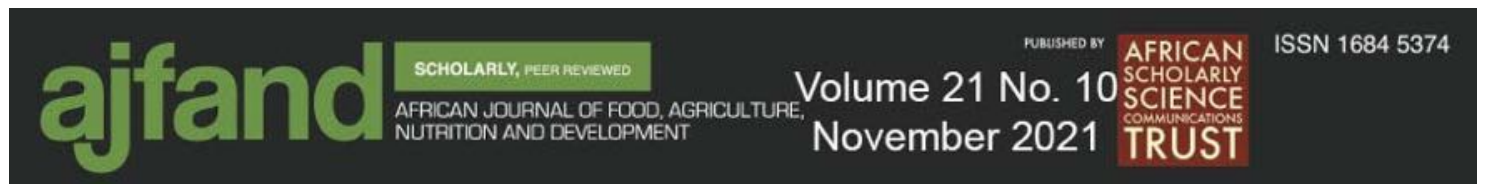

Afr. J. Food Agric. Nutr. Dev. 2021; 21(10): 18824-18838 https://doi.org/10.18697/ajfand.105.19555

\title{
ASSOCIATION BETWEEN NUTRITION KNOWLEDGE, LIFESTYLE, DIETARY PRACTICES AND NUTRITIONAL STATUS AMONG CIVIL SERVANTS IN WESTERN NIGERIA
}

Akinmoladun $\mathrm{OF}^{1,2 *}$, Oluyede $\mathrm{OJ}^{1}$, Femi $\mathrm{FA}^{3}$, Olaitan $\mathrm{OO}^{1}$ and $\mathrm{CN}$ Nesamvuni ${ }^{2}$

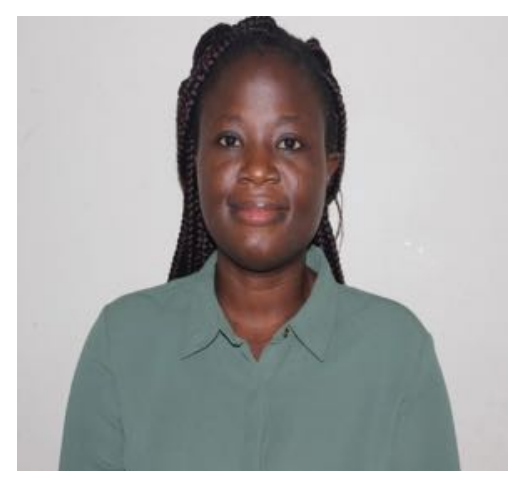

Funmi Akinmoladun

*Corresponding author email: seunfunmion71@gmail.com

${ }^{1}$ Nutrition and Dietetics Unit, Department of Food Science and Technology, Wesley University, PMB 507 Ondo, Ondo State, Nigeria

${ }^{2}$ Department of Nutrition, School of Health Sciences, University of Venda, Private Bag X5050, Thohoyandou 0950, South Africa

${ }^{3}$ Department of Food Science and Technology, School of Agriculture and Agricultural Technology, Federal University of Technology, PMB 65 Minna, Niger State, Nigeria 


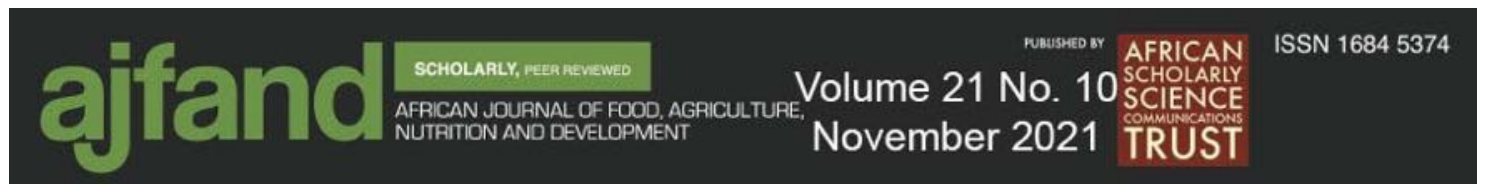

\begin{abstract}
Nutrition knowledge plays a crucial role in promoting healthier eating practices, leading to the maintenance of healthy body weight. This is because knowledge of dietary guidelines and healthy eating habits among adults has been positively correlated. However, in terms of dietary habits, presumptions that the supposed civil servants in some parts of Western Nigeria are knowledgeable about basic dietary practices are yet to be explored. Therefore, this study was designed to assess the nutrition knowledge, lifestyle, dietary practices, and nutritional status among men and women civil servants in Ado, Ekiti State, Nigeria. A structured interviewer questionnaire was administered to civil servants (180 male and 220 female elderly respondents, $\leq 60$ years old) to collect data on economic and socio-demographic characteristics, nutrition knowledge, lifestyle, and dietary habits. Anthropometric measurements were also taken. The quantitative were coded, collated, and analyzed using SPSS. Descriptive statistics were used to summarize data from categorical variables. Chi-square test, at a 5\% confidence level, was used to establish any significant relationship between food intake parameters and nutrition knowledge. Most of the respondents $(66.7 \%)$ were affected by the delayed payment of their monthly salaries. The total knowledge scores revealed that $13.25 \%, 41.25 \%$ and $45.50 \%$ of the respondents had poor, fair and good nutrition knowledge, respectively. Unfortunately, this higher nutrition knowledge does not translate into good dietary habits. Data obtained revealed bad eating habits, as a more significant percentage of the respondents regularly ate high-fat foods $(99.5 \%)$, ate outside the home $(85.3 \%)$ and did not take vegetables $(83.3 \%)$ nor fruits $(60 \%)$ daily. There exists, however, a significant and positive relationship between nutrition knowledge and physical activity $(\mathrm{P}=0.043)$, high-fat foods consumption $(\mathrm{P}<0.001)$, daily fruits consumption $(\mathrm{P}<0.001)$ and vegetable consumption $(\mathrm{P}<0.001)$. In conclusion, the discrepancy between the respondents' high nutrition knowledge and their seemingly poor lifestyle and dietary behaviour show that nutrition knowledge alone does not translate into good dietary behaviour.
\end{abstract}

Key words: Nutrition knowledge, dietary practices, civil servants, obesity, lifestyle, nutritional status, BMI, cardiovascular diseases 


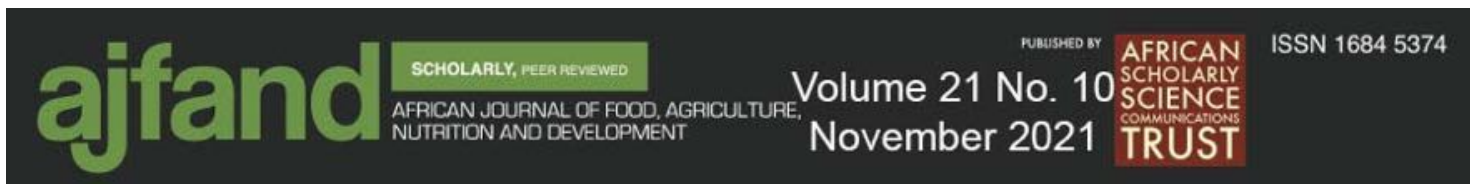

\section{INTRODUCTION}

Most mortality cases worldwide are traceable to so many preventable diseases that could easily be avoided through a healthy lifestyle, adequate nourishment, consistent physical activity, and stress management [1]. Nutrition knowledge plays a significant role in advancing healthy eating habits by ensuring that essential nutrient requirements are met to prevent malnutrition [2]. People who are aware of the relationships between specific health conditions and poor nutrition are better positioned to watch and manage their weight through their diet choice. As pointed out, knowledge of dietary guidelines and healthy eating habits among adults are positively correlated [3]. A change in eating behaviour starts from the awareness of the significance of healthy eating behaviour and knowledge of the types of food to eat. However, the relationship between what people do and what they know is weak. This is because knowledge per se does not automatically produce a behavioural change in humans but can act as a powerful instrument when people decide to change [1].

Factors that usually influence malnutrition include socioeconomic status, gender, age, ethnicity, education level, and area of residence [2]. Based on studies, the nature of a job or work can sometimes lead to an inactive lifestyle with little or insufficient physical activity, thus increasing the chances of becoming obese and overweight $[2,4]$. Poor dietary habits among working-class adults have been reported to be a looming lifestyle crisis. Based on reported studies, the consequences of physical inactivity among young adults due to poor nutrition knowledge can be reduced through awareness and education on excellent nutrition information that will cause dietary behavioural change [5].

The beneficial effects of nutrition knowledge in adulthood have increased over the past decade, and studies have established a positive relationship between food nutrient consumption and nutrition knowledge [6]. However, according to the report, skilled workers, including civil servants presumed to be knowledgeable about dietary guidelines and practices, have been classified as a high-risk group for over-nutrition [7]. Also, Oladoyinbo et al. [8] affirmed that cases of overweight and obesity are more prevalent among the female gender. Given the high prevalence of civil servants among the skilled workers in the study area, there is a gap in understanding the extent of nutrition knowledge and the relationship between nutrition knowledge and nutritional status among civil servants. Hence, this paper seeks to assess the nutritional status, nutrition knowledge and lifestyle among civil servants in Ado-Ekiti, a state in western Nigeria.

\section{MATERIALS AND METHODS}

\section{Ethical clearance}

This investigation was approved by the Ethics and Research Committee of Ekiti State University Teaching Hospital (Protocol No: EKSUTH/A67/201810/005). 


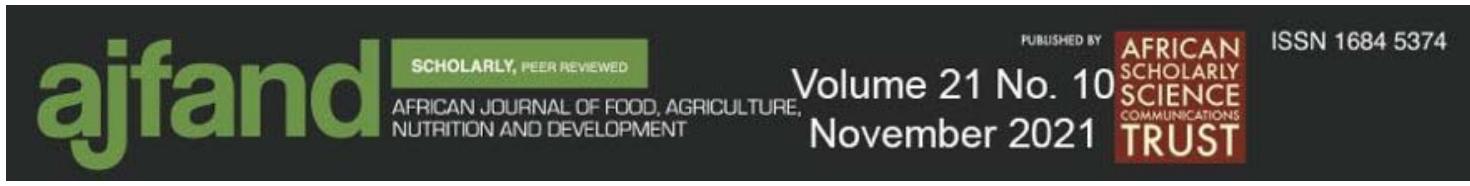

\section{Study area and design}

The study was conducted in Ado-Ekiti State, Nigeria. The study was cross-sectional and descriptive in nature.

\section{Population, sample size and sampling technique}

The study population included selected civil servants in the study area. A simple random sampling technique was used to determine a sample size (n) total of 390 respondents $(\sim 400)$ for the study using Yamane's formula [9] at a confidence level of $95 \%$. The formula is as follows:

$$
n=\frac{N}{1+N(e)^{2}}
$$

where $\mathrm{e}=$ margin of error $(5 \%)$ and $\mathrm{N}=$ population size $(15600)$.

\section{Data collection and anthropometric measurements}

A structured, interviewer-administered questionnaire was used to gather information on socio-demographic, economic characteristics, nutrition knowledge, lifestyle, and dietary habits. Anthropometric measurements (weights and heights) of the respondents were also taken and recorded. Weight was measured $( \pm 0.1 \mathrm{~kg})$ using the SECA weighing scale (Seca 769, CE 0123) and height $( \pm 0.1 \mathrm{~kg})$ with a stadiometer. Body mass index (BMI) was calculated by dividing weight $(\mathrm{kg})$ by height $\left(\mathrm{m}^{2}\right)$. Respondents with a BMI $<18.5 \mathrm{~kg} / \mathrm{m}^{2}$ were categorized as underweight, $18.5-24.99 \mathrm{~kg} / \mathrm{m}^{2}$ as normal, $25.0-29.9 \mathrm{~kg} / \mathrm{m}^{2}$ as overweight, and BMI $\geq 30.0 \mathrm{~kg} / \mathrm{m}^{2}$ as obese. Waist circumference (WC) and hip circumference (HC) were measured using a steel measuring tape. The measurements were made halfway between the iliac crest and lower border of the ribs, and values obtained were used in calculating the waist: hip ratio $(\mathrm{WC} / \mathrm{HC})$.

\section{Nutrition knowledge of the respondents}

The general nutrition-knowledge questionnaire comprising 24 questions and scaled from strongly disagree to strongly agree [10] was used to assess the respondents' nutrition knowledge. A pre-trial questionnaire assessment was conducted on the civil servants outside the location for effective time management and to help detect any inherent flaws and mistakes. The possible score of each nutrition knowledge question was 0 (low nutrition knowledge) or 1 (high nutrition knowledge). The knowledge scores were added and grouped as poor $(\leq 8)$, fair (8-15) and good $(\geq 16)$ knowledge.

\section{Data analysis}

Data obtained were cleaned and keyed into the Statistical Package for Social Sciences (SPSS, version 17) database for analysis. Descriptive statistics were used to establish measures of central tendencies, variability, and deviations [11]. A Chi-square test was used to determine the association between dependent and independent variables. Analyzed data were considered significant at $\mathrm{P}<0.05$.

\section{RESULTS AND DISCUSSION}

The socio-demographic characteristics of the respondents are presented in Table 1. Most of the respondents were females (55.0\%), and 39.5\% of the respondents' age ranged between $40-49$ years. 


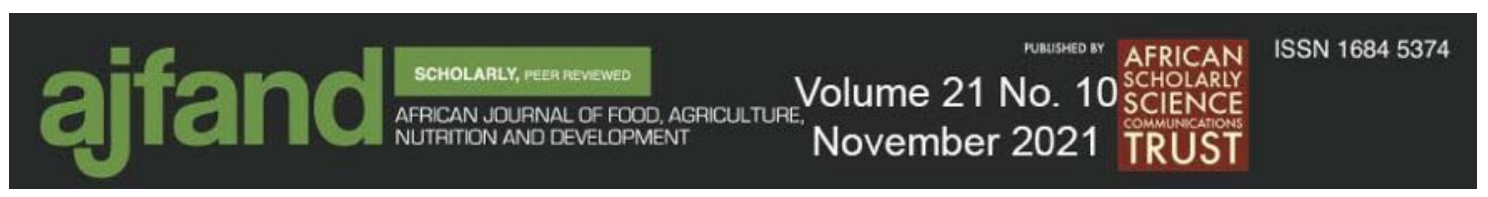

A more significant percentage of the respondents' (66.75\%) family food intake was affected by delayed payment of salary, and this negatively impacted the majority $(57.5 \%)$ of the respondents (Table 2). The personal food intake of the respondents $(75.5 \%)$ was affected by non-payment of salary. The delay in the salary payment undermined the family food intake, basically on the varieties and quality of consumed food and not on the quantity.

The nutritional knowledge of the respondents ranged from poor (13.25\%), fair $(41.25 \%)$ to good $(45.5 \%)$, based on the scale of measurement used (Table 3$)$. The association between nutrition knowledge and gender was not significant $(\mathrm{P}=0.933)$. The respondents' higher level of good and fair nutrition knowledge might have been due to their higher education level, as the respondents used in this survey were civil servants. Highly educated civil servants are more likely to become aware of the importance of healthy nutrition during their educational journey. However, educational level alone is assumed to be an independent determinant of nutrition knowledge, but when complemented with high financial status, the impact on nutrition knowledge is vast due to the availability of tablets, computers, smartphones and the internet [12].

The nutritional status of the respondents is presented in Table 4. None of the respondents was underweight. More males (13.3\%) than females (3.6\%) were obese. The higher prevalence of overweight among the male civil servants than females in this study agrees with what was reported among Ijebu Ode's traders in Nigeria [8]. This, however, contradicts other reported studies that obesity is strongly correlated with the female gender [13]. The higher obesity among the male respondents may be due to increased alcohol consumption and out-of-home meals among the male civil servants in this study. These factors could significantly impact the average BMIs. This is also evident with waist/hip ratio $>0.89$ among the male. The $8 \%$ prevalence of obesity among civil servants could be partially explained by the low level of regular physical exercise. Skilled workers have been classified as a high-risk group for obesity and overweight, which are risk factors for cardiovascular disease due to their unhealthy dietary practices and the static nature of their job [7]. The results in this study suggest that civil servants are indeed one group of the population that could be at risk of obesity and overweight and its related aftermaths of diabetes and hypertension. This result, however, contradicts what should be expected because, generally, civil servants are highly educated and have greater chances of obtaining nutrition and healthy behavioural information. Hence, one would anticipate better results and lifestyle indicators for skilled workers than the general population [14]. This finding supports previous work that proposed a statistically significant association between high socioeconomic status and obesity [15]. It is reasonable that increased socioeconomic status among civil servants contributed proportionally to the high prevalence of obesity and overweight among this study's respondents. Moreover, most civil servants assessed in this study were not engaged in any vigorous physical activity (that is, living a sedentary lifestyle). Similar studies also confirm an increasing trend of obesity and overweight among sedentary respondents and those engaged in little activities [4,16]. This study's non-underweight prevalence differed from $6.7 \%$ [17] and 10.4\% [18] among adults in sub-urban northern Nigeria. 


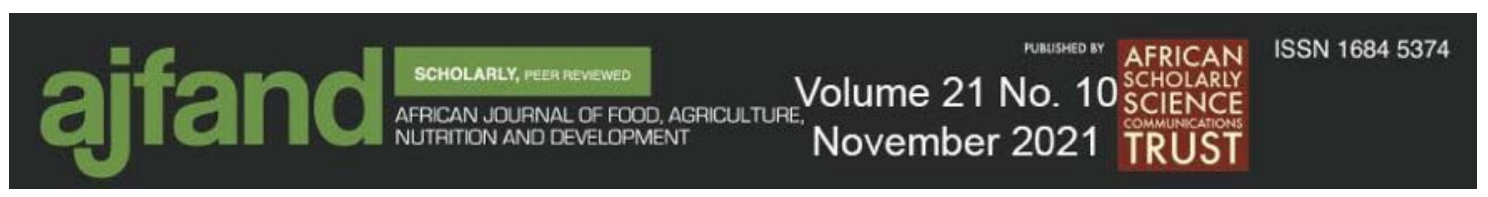

There was no significant association $(\mathrm{P}=0.191)$ between the respondents' nutritional knowledge and nutritional status (Table 5). Based on studies, nutrition knowledge is reported to have a significant independent association with BMI and proportional to physical activity level and inversely related to BMI [19]. This is contrary to this study's result, as there was no significant relationship between BMI classification and nutrition knowledge. This implies that nutrition knowledge did not affect their dietary practices as well as BMI. A research study conducted on Belgian women [20] supports the positive association between physical activity and nutrition knowledge and the negative relationship between BMI and nutrition knowledge in this study. In a similar vein, Mediterranean dietary behaviour is significantly related to nutrition knowledge and healthy dietary practices [21]. In other studies, nutrition knowledge is negatively associated with BMI and obesity [22]. In general, studies have shown that obesity and overweight can be prevented by diet through (i) increasing satiety by a vast quantity of dietary fibre, (ii) a low glycemic load and low energy density or (iii) larger intake of mono-unsaturated fatty acids which improve metabolism of glucose [22].

The lifestyle and dietary habits of the respondents are presented in Table 6 . There is a significant relationship between gender and daily vegetable consumption $(\mathrm{P}=0.014)$ and frequency of fatty foods consumption $(\mathrm{P}=0.009)$. This non-significant difference between nutritional knowledge and gender contravenes some reported studies, indicating that men have lower dietary knowledge than women [23]. A study conducted on some Taiwanese people revealed that older men had higher education and nutrition knowledge than women [24]. Still, others have reported that women have higher nutrition knowledge than men [25]. This higher nutrition knowledge in women is related to their food preparation and purchasing roles compared to men's little interest in nutrition. Like this study's findings, no differences were observed in nutritional knowledge between women and men in American and Genevan populations [26]. The non-gender differences in nutrition knowledge among our respondents may be a result of their educational level. Also, public discussions of healthy eating habits on media cannot be neglected.

There was a significant relationship $(\mathrm{P}<0.05)$ between nutrition knowledge and: dietary practices, physical activity performance $(\mathrm{P}=0.043)$, fatty foods consumption $(\mathrm{P} \leq 0.001)$, frequency of eating outside $(\mathrm{P} \leq 0.001)$, fruits and vegetables consumption $(\mathrm{P} \leq 0.001)$, soft drinks and fast-food consumption $(\mathrm{P} \leq 0.001)$, body weight satisfaction $(\mathrm{P} \leq 0.001)$, cigarette smoking and alcohol consumption $(\mathrm{P} \leq 0.001)$, nutrition supplements and consumption of three-square meals per day $(\mathrm{P}=0.031)$ ) (Table 7). More females in this study engaged in the consumption of high fatty foods than their male counterparts. Exercise and physical activity promote individuals' overall health by increasing strength and energy, improving mental and physical well-being, weight loss promotion, and illness prevention [27].

The data obtained in this study revealed terrible eating habits as a more significant percentage of the respondents always ate fatty foods and usually ate outside the home. However, there was a gender difference in daily fruits consumption as more males took fruits every day than females. The low consumption of soft/mineral drinks and fast 


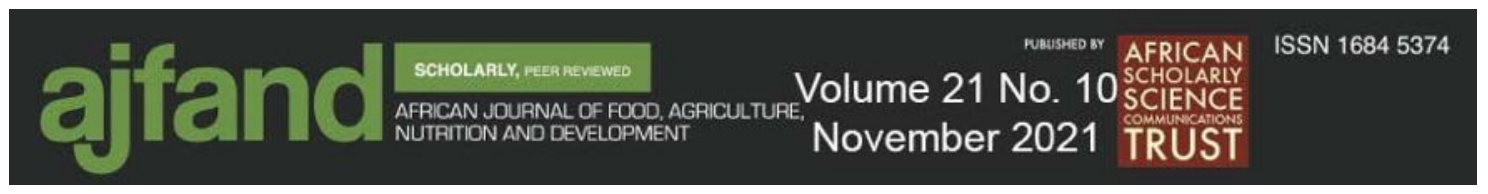

foods by the respondents was encouraging. Similarly, low consumption of soft drinks and fast foods among students has also been reported [28]. A low incidence of alcohol and cigarette use could be considered a healthy lifestyle among the respondents. The observed gender differential in alcohol consumers and cigarette smokers in this study agrees with the earlier report that males were more likely to smoke and drink alcohol than females [18]. Alcohol has been described as the most used psychoactive drug in Nigeria. Its excessive consumption is linked to major depressive disorders among young adults and is a strong risk factor for stroke in adults above 45 years [29].

The majority of the respondents that had good knowledge of healthy foods consumed fatty foods always. This may be a result of problems with conveying nutrition knowledge into practice [30]. Also, better nutrition knowledge related to fruits and vegetable consumption, daily consumption of soft drinks, and fast-food consumption were high among the respondents. A significant positive relationship was reported in a similar study between high nutrition knowledge, a lower intake of sweetened drinks, and a higher intake of cereals, fish, fibre and calcium [31]. Studies indicated a healthy lifestyle to include adequate nutrition, such as taking some portions of fruits and vegetables per day, adequate physical activity, and avoiding tobacco or alcohol abuse [32]. Skipping a meal has been identified as a lifestyle factor that inhibits good nutrition. It results in inadequate nutrient intake and can promote reliance on "junk" foods. In this study, meal skipping was higher in males than in female civil servants. Similar results have been reported on male teachers skipping meals than their female counterparts [18]. Although the type of meal being neglected was not assessed in this research, lunch appears to be the most skipped meal than breakfast among Nigerians. A minority of the civil servants in this study took nutrient supplements compared to more than half of the respondents in a similar study [18].

\section{CONCLUSION}

The study revealed that a more significant percentage of the respondents had good nutrition knowledge. However, such knowledge did not reflect their lifestyle and dietary practice as most respondents had unsatisfactory dietary practices. The respondents' nutritional status revealed a higher proportion of obese males compared to females, and such findings could have important health implications. In addition, there was no association between the nutritional status and knowledge of the respondents.

\section{Conflict of Interest}

The authors declare no potential conflict of interest. 


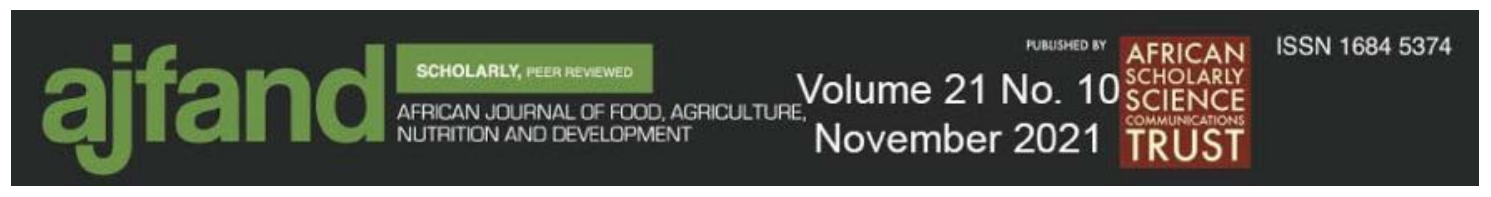

Table 1: Socio-demographic characteristics of the respondents

\begin{tabular}{|c|c|c|}
\hline Variables & Frequency & Percentage \\
\hline \multicolumn{3}{|l|}{ Sex } \\
\hline Male & 180 & 45 \\
\hline Female & 220 & 55 \\
\hline \multicolumn{3}{|l|}{ Age (years) } \\
\hline Mean (SD) & $2.83(1.089)$ & \\
\hline $20-39$ & 72 & 8 \\
\hline $30-39$ & 52 & 13 \\
\hline $40-49$ & 158 & 39.5 \\
\hline $50-59$ & 109 & 27.25 \\
\hline $60-69$ & 9 & 2.25 \\
\hline \multicolumn{3}{|l|}{ Marital status } \\
\hline Single & 74 & 18.5 \\
\hline Separated & 60 & 15 \\
\hline Divorced & 51 & 12.75 \\
\hline Married & 189 & 47.25 \\
\hline Widowed & 26 & 6.5 \\
\hline \multicolumn{3}{|l|}{ State of origin } \\
\hline Edo & 37 & 9.25 \\
\hline Ekiti & 259 & 64.75 \\
\hline Lagos & 13 & 3.25 \\
\hline Ondo & 14 & 3.5 \\
\hline Osun & 36 & 9 \\
\hline Akwa-Ibom & 9 & 2.25 \\
\hline Oyо & 32 & 8 \\
\hline \multicolumn{3}{|l|}{ Ethnicity } \\
\hline Yoruba & 355 & 88.75 \\
\hline Igbo & 36 & 9 \\
\hline Other & 9 & 2.25 \\
\hline \multicolumn{3}{|l|}{ Religion } \\
\hline Christian & 269 & 67.25 \\
\hline Islam & 118 & 29.5 \\
\hline Traditionalist & 13 & 3.25 \\
\hline
\end{tabular}




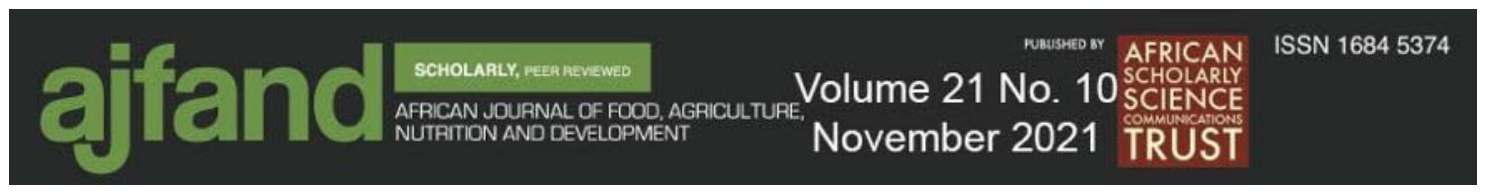

Table 2: Socio-economic characteristics of the respondents

\begin{tabular}{lll}
\hline Variables & Frequency & Percentage \\
\hline Average Monthly Income (\#) & $2.38(1.053)$ & \\
Mean (SD) & 112 & 28.0 \\
$10,000-20,000$ & 87 & 21.75 \\
$20,000-50,000$ & 139 & 34.75 \\
$50,000-100000$ & 62 & 15.5 \\
$>100000$ & \\
Delayed-payment of salary affects family food intake & 66.75 \\
Yes & 267 & 32.25 \\
No & 133 & \\
If yes, how does it affect you & & 9.25 \\
Positively & 37 & 57.5 \\
Negatively & 230 & 33.25 \\
Nil & 133 & \\
Delayed-payment of salary affects personal food intake & 75.5 \\
Yes & 302 & 24.5 \\
No & 98 & \\
If yes, how? & & 13.5 \\
Positively & 54 & 62.0 \\
Negatively & 248 & 24.5 \\
Nil & 98 & \\
\hline
\end{tabular}

Table 3: Nutrition knowledge of the respondents

\begin{tabular}{llllll}
\hline $\begin{array}{l}\text { Nutrition } \\
\text { Knowledge }\end{array}$ & Male (n \%) & Female (n \%) & Total & $\mathrm{X}^{2}(\mathrm{df})$ & P-value \\
\hline $\begin{array}{l}\text { Knowledge } \\
\text { classification }\end{array}$ & & & 400 & $0.1392(2)$ & 0.933 \\
Poor & $25(13.9)$ & $28(12.7)$ & & & \\
Fair & $73(40.6)$ & $92(41.8)$ & & & \\
Good & $82(45.6)$ & $100(45.5)$ & & & \\
\hline
\end{tabular}

Table 4: Nutritional status of the respondents

\begin{tabular}{lccccc}
\hline Nutritional Status & Male (\%) & Female (\%) & Total & $\mathrm{X}^{2}(\mathrm{df})$ & P-value \\
\hline BMI classification $\left(\mathrm{kg} / \mathrm{m}^{2}\right)$ & & & & $14.249(2)$ & 0.001 \\
& & & & \\
& & & & \\
$<18.5$ & 0 & 0 & 0 & & \\
$18.5-24.9$ & $69(38.3)$ & $108(49.1)$ & $177(44.25)$ & & \\
$25-29.9$ & $87(48.3)$ & $104(47.3)$ & $191(47.75)$ & & 0.003 \\
$30-34.9$ & $24(13.3)$ & $8(3.6)$ & $32(8.0 \%)$ & & \\
Waist/Hip ratio & & & 400 & $11.602(2)$ & \\
& & & & \\
0.80 & $57(31.7)$ & $106(48.2)$ & $163(40.75 \%)$ & & \\
$0.80-0.89$ & $93(51.7)$ & $82(37.3)$ & $175(43.75 \%)$ & & \\
$>0.89$ & $30(16.7)$ & $32(14.5)$ & $62(15.5 \%)$ & & \\
\hline
\end{tabular}




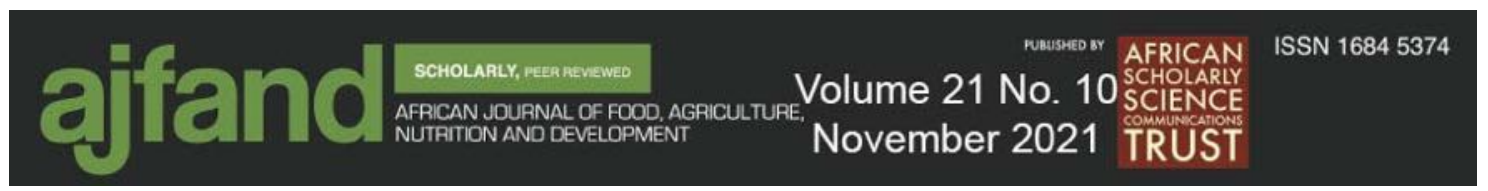

Table 5: Association between nutrition knowledge and nutritional status of the respondents

\begin{tabular}{|c|c|c|c|c|c|c|c|c|c|}
\hline \multirow{3}{*}{$\begin{array}{l}\text { Nutritional } \\
\text { Status }\end{array}$} & \multicolumn{6}{|c|}{ Nutrition Knowledge } & \multirow[b]{3}{*}{ total } & \multirow[b]{3}{*}{$x^{2}(d f)$} & \multirow{3}{*}{$\begin{array}{l}\mathrm{P} \text { - } \\
\text { value }\end{array}$} \\
\hline & \multicolumn{2}{|c|}{ Poor } & \multicolumn{2}{|c|}{ Fair } & \multicolumn{2}{|c|}{ Good } & & & \\
\hline & M (\%) & $\mathrm{F}(\%)$ & M (\%) & $\mathrm{F}(\%)$ & M (\%) & $\mathrm{F}(\%)$ & & & \\
\hline BMI & & & & & & & 400 & $6.118(4)$ & 0.191 \\
\hline Classification & & & & & & & & & \\
\hline$<18.5$ & 0 & 0 & 0 & 0 & 0 & 0 & & & \\
\hline $18.5-24.99$ & $7(3.89)$ & $15(6.82)$ & $17(9.44)$ & $50(22.73)$ & $45(25.0)$ & $43(19.55)$ & & & \\
\hline $25-29.9$ & $14(7.78)$ & $13(5.91)$ & $42(23.33)$ & $37(16.82)$ & $31(17.22)$ & $54(24.55)$ & & & \\
\hline $30-34.9$ & $4(2.22)$ & 0 & $14(7.78)$ & $5(2.27)$ & $6(3.33)$ & $3(1.36)$ & & & \\
\hline Waist/hip ratio & & & & & & & 400 & $4.841(4)$ & 0.304 \\
\hline$<0.8$ & $9(5.0)$ & $15(6.82)$ & $26(14.44)$ & $43(19.55)$ & $22(12.22)$ & $48(21.82)$ & & & \\
\hline $0.8-0.89$ & $16(8.89)$ & $9(4.09)$ & $40(22.22)$ & $33(15.0)$ & $37(20.56)$ & $40(18.18)$ & & & \\
\hline$>0.89$ & 0 & $4(1.82)$ & $7(3.89)$ & $16(7.27)$ & $23(12.78)$ & $12(5.45)$ & & & \\
\hline
\end{tabular}

$\mathrm{M}=$ male; $\mathrm{F}=$ female

Table 6: Lifestyle and dietary practice of respondents

\begin{tabular}{|c|c|c|c|c|c|}
\hline Dietary Practice & $M(n)$ & $\mathrm{F}(\mathrm{n})$ & Total & $\mathrm{X}^{2}(\mathrm{df})$ & P-value \\
\hline Do you perform physical exercise? & & & 400 & $0.775(1)$ & 0.379 \\
\hline Yes & $84(46.7)$ & $93(42.3)$ & & & \\
\hline No & $96(53.3)$ & $127(57.7)$ & & & \\
\hline Do you take fatty foods? & & & 400 & $2.457(1)$ & 0.117 \\
\hline Yes & 178(98.9) & $220(100.0)$ & & & \\
\hline No & $2(1.1)$ & 0 & & & \\
\hline Do you normally eat outside the home? & & & 400 & $1.591(1)$ & 0.207 \\
\hline Yes & $149(82.8)$ & 192(87.3) & & & \\
\hline No & $31(17.2)$ & $28(12.7)$ & & & \\
\hline Do you take fruits every day? & & & 400 & $1.515(1)$ & 0.218 \\
\hline Yes & $78(43.3)$ & $82(37.3)$ & & & \\
\hline No & $102(56.7)$ & $138(62.7)$ & & & \\
\hline Do you take vegetable every day? & & & 400 & 6.065 & 0.014 \\
\hline Yes & 21(11.7) & $46(20.9)$ & & & \\
\hline No & $159(88.3)$ & $174(79.1)$ & & & \\
\hline Do you take soft drinks every day? & & & 400 & $2.116(3)$ & 0.549 \\
\hline Yes & $4(2.2)$ & $8(3.6)$ & & & \\
\hline No & $3(1.7)$ & $1(0.5)$ & & & \\
\hline Before & $5(2.8)$ & $6(2.7)$ & & & \\
\hline Nil & $168(93.3)$ & $205(93.2)$ & & & \\
\hline Do you take Fast foods? & & & 400 & $2.911(3)$ & 0.406 \\
\hline Yes & $85(47.2)$ & $106(48.2)$ & & & \\
\hline No & $95(52.8)$ & $112(50.9)$ & & & \\
\hline Nil & 0 & $2(0.9)$ & & & \\
\hline $\begin{array}{l}\text { Are you satisfied with your body } \\
\text { weight? }\end{array}$ & & & 400 & $0.263(1)$ & 0.608 \\
\hline Yes & $87(48.3)$ & $112(50.9)$ & & & \\
\hline
\end{tabular}




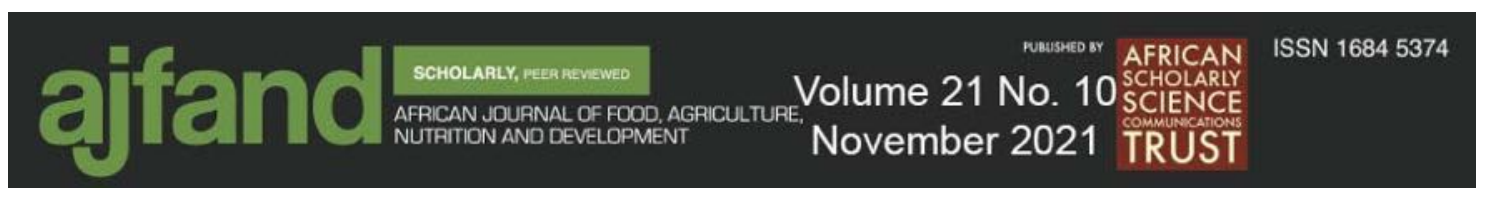

\begin{tabular}{llllll}
\hline No & $93(51.7)$ & $108(49.1)$ & & & \\
Do you smoke Cigarette? & & & 400 & $3.354(2)$ & 0.187 \\
Yes & $34(18.9)$ & $27(12.3)$ & & & \\
No & $130(72.2)$ & $172(78.2)$ & & & \\
Before & $16(8.9)$ & $21(9.5)$ & 400 & $5.792(2)$ & 0.055 \\
Do you drink alcohol? & & & & \\
Yes & $93(51.7)$ & $107(48.6)$ & & & \\
No & $70(38.9)$ & $74(33.6)$ & & & \\
Before & $17(9.4)$ & $39(17.7)$ & 400 & $0.449(1)$ & 0.503 \\
Do you take nutritional supplement? & & & & \\
Yes & $16(8.9)$ & $24(10.9)$ & & & \\
No & $164(91.1)$ & $196(89.1)$ & & & \\
Do you eat three meals per day? & & & & \\
Yes & $126(70.0)$ & $171(77.7)$ & 400 & $3.093)(1)$ & 0.079 \\
No & $54(30)$ & $49(22.3)$ & & & \\
\hline
\end{tabular}

$\mathrm{M}=$ male; $\mathrm{F}=$ female

Table 7: Association between dietary practice and nutrition knowledge

\begin{tabular}{|c|c|c|c|c|c|c|c|c|c|}
\hline \multirow[t]{2}{*}{ Dietary practice } & \multicolumn{2}{|c|}{ Poor } & \multicolumn{2}{|c|}{ Fair } & \multicolumn{2}{|c|}{ Good } & \multirow[b]{2}{*}{ Total } & \multicolumn{2}{|c|}{ P-value } \\
\hline & $\mathrm{M}$ & $\mathrm{F}$ & $\mathrm{M}$ & $\mathrm{F}$ & $\mathrm{M}$ & $\mathrm{F}$ & & $X^{2}(\mathrm{df})$ & \\
\hline Physical exercise performance & & & & & & & 400 & $6.285(2)$ & $0.043^{*}$ \\
\hline Yes & 8 & 8 & 41 & 41 & 35 & 44 & & & \\
\hline No & 17 & 20 & 32 & 51 & 47 & 56 & & & \\
\hline Fatty food consumption & & & & & & & 400 & $2.408(2)$ & 0.300 \\
\hline Yes & 25 & 28 & 73 & 92 & 80 & 100 & & & \\
\hline No & 0 & 0 & 0 & 0 & 2 & 0 & & & \\
\hline $\begin{array}{l}\text { Frequency of fatty foods } \\
\text { consumption }\end{array}$ & & & & & & & 400 & $23.291(6)$ & $0.001^{*}$ \\
\hline Always & 20 & 25 & 37 & 60 & 53 & 81 & & & \\
\hline Often & 3 & 1 & 23 & 19 & 9 & 11 & & & \\
\hline Seldom & 2 & 2 & 13 & 13 & 18 & 8 & & & \\
\hline Nil & 0 & 0 & 0 & 0 & 0 & 0 & & & \\
\hline $\begin{array}{l}\text { Attitude to eating outside the } \\
\text { home }\end{array}$ & & & & & & & 400 & $4.258(2)$ & 0.119 \\
\hline Yes & 24 & 26 & 60 & 80 & 65 & 85 & & & \\
\hline No & 1 & 2 & 13 & 12 & 17 & 14 & & & \\
\hline Frequency of eaten outside & & & & & & & 400 & $54.717(6)$ & $<0.001^{*}$ \\
\hline Always & 11 & 19 & 22 & 41 & 10 & 20 & & & \\
\hline Often & 10 & 6 & 17 & 25 & 44 & 53 & & & \\
\hline Seldom & 3 & 1 & 21 & 15 & 11 & 14 & & & \\
\hline Nil & 1 & 2 & 13 & 11 & 17 & 13 & & & \\
\hline Response to fruit consumption & & & & & & & 400 & $18.276(2)$ & $<0.001^{*}$ \\
\hline Yes & 4 & 3 & 38 & 35 & 36 & 44 & & & \\
\hline No & 21 & 25 & 35 & 57 & 46 & 56 & & & \\
\hline $\begin{array}{l}\text { Response to vegetable } \\
\text { consumption everyday }\end{array}$ & & & & & & & 400 & $36.174(2)$ & $<0.001^{*}$ \\
\hline Yes & 7 & 15 & 12 & 20 & 2 & 11 & & & \\
\hline No & 18 & 13 & 61 & 72 & 80 & 89 & & & \\
\hline
\end{tabular}




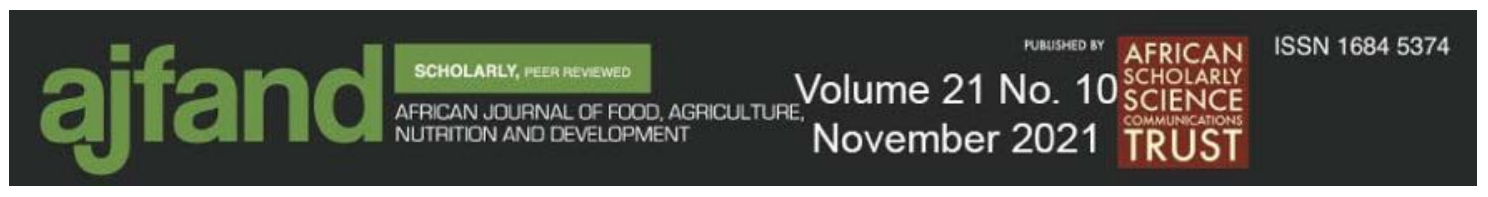

\begin{tabular}{|c|c|c|c|c|c|c|c|c|c|}
\hline $\begin{array}{l}\text { Response to soft drinks } \\
\text { consumption daily }\end{array}$ & & & & & & & 400 & $32.860(6)$ & $<0.001^{*}$ \\
\hline Yes & 1 & 6 & 1 & 1 & 2 & 1 & & & \\
\hline No & 0 & 0 & 0 & 0 & 2 & 1 & & & \\
\hline Before & 0 & 0 & 4 & 5 & 1 & 1 & & & \\
\hline Nil & 24 & 22 & 68 & 86 & 77 & 97 & & & \\
\hline $\begin{array}{l}\text { Response to fast foods } \\
\text { consumption }\end{array}$ & & & & & & & 400 & $39.759(4)$ & $<0.001^{*}$ \\
\hline Yes & 4 & 6 & 32 & 35 & 49 & 65 & & & \\
\hline No & 21 & 22 & 41 & 55 & 33 & 35 & & & \\
\hline Nil & 0 & 0 & 0 & 2 & 0 & 0 & & & \\
\hline $\begin{array}{l}\text { Response to bodyweight } \\
\text { satisfaction }\end{array}$ & & & & & & & 400 & $47.511(2)$ & $<0.001^{*}$ \\
\hline Yes & 3 & 5 & 32 & 39 & 52 & 68 & & & \\
\hline No & 22 & 23 & 41 & 53 & 30 & 32 & & & \\
\hline Response to cigarette smoking & & & & & & & 400 & $23.269(4)$ & $<0.001^{*}$ \\
\hline Yes & 5 & 2 & 8 & 13 & 21 & 12 & & & \\
\hline No & 15 & 20 & 56 & 66 & 59 & 86 & & & \\
\hline Before & 5 & 6 & 9 & 13 & 2 & 2 & & & \\
\hline $\begin{array}{l}\text { Response to alcohol } \\
\text { consumption }\end{array}$ & & & & & & & 400 & $56.597(4)$ & $<0.001^{*}$ \\
\hline Yes & 8 & 6 & 34 & 33 & 51 & 68 & & & \\
\hline No & 10 & 9 & 30 & 39 & 30 & 26 & & & \\
\hline Before & 7 & 13 & 9 & 20 & 1 & 6 & & & \\
\hline Total & 25 & 28 & 73 & 92 & 82 & 100 & & & \\
\hline $\begin{array}{l}\text { Response to nutrition } \\
\text { supplement }\end{array}$ & & & & & & & 400 & $10.707(2)$ & $0.005^{*}$ \\
\hline Yes & 0 & 2 & 11 & 15 & 5 & 7 & & & \\
\hline No & 25 & 26 & 62 & 77 & 77 & 93 & & & \\
\hline $\begin{array}{l}\text { Response to three meals } \\
\text { consumption per day }\end{array}$ & & & & & & & 400 & $6.926(2)$ & $0.031^{*}$ \\
\hline Yes & 21 & 26 & 53 & 68 & 52 & 77 & & & \\
\hline No & 4 & 2 & 20 & 24 & 30 & 23 & & & \\
\hline
\end{tabular}

$\mathrm{M}=$ male; $\mathrm{F}=$ female 


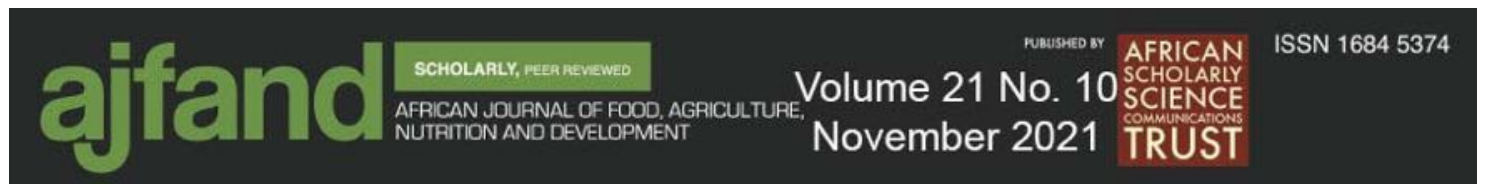

\section{REFERENCES}

1. Botelho SF, Martins MAP and AMM Reis Analysis of New Drugs Registered in Brazil from the perspective of the Unified Health System and the burden of diseases. Ciencia \& Saude Coletica 2018; 23(1): 215 - 228.

2. Kruger HS, Venter CS, Vorster HH and BM Margetts Physical inactivity is the major determinant of obesity in black women in the North West Province, South Africa: The THUSA study. Nutrition 2002; 18(5): 422-427.

3. Kolodinsky J, Harvey-Berino JR, Berlin L, Johnson RK and TW Reynolds Knowledge of current dietary guidelines and food choice by college students: Better eaters have higher knowledge of dietary guidance. J. Am. Diet. Assoc. 2007; 107(8):1409-1413.

4. Olaitan OO, Olanrewaju OI, Akinmoladun FO and GT Fadupin Central Obesity and Stress-Predisposing Factors to Hypertension among Health Workers in Jos University Teaching Hospital, Plateau State, Nigeria. Curr Res Diabetes Obes J. 2020;12(4):111-6.

5. Worsley A Nutrition knowledge and food consumption: Can nutrition knowledge change food behaviour? Asia Pac. J. Clin. Nutr. 2002;11(s3): S579-S585.

6. Mason A and RL Spoth Longitudinal associations of alcohol involvement with subjective well-being in adolescence and prediction to alcohol problems in early adulthood. J. Youth Adolesc. 2011; 40(9):1215-1224.

7. Kim JY, Park YH and EN An The relationship between lifestyle and obesity of office workers in Korea. Int. J. Control Autom. 2015; 8(10):349-60.

8. Oladoyinbo CA, Eherette NN and TI Ogunubi Obesity and hypertension among traders in Ijebu Ode, Nigeria. Afr. J. Biomed. Res. 2015; 18:23-27.

9. Yamane T Statistics, an introductory analysis, $2^{\text {nd }}$ Ed., New York: Harper and Row. 1967.

10. Parmenter $\mathbf{K}$ and $\mathbf{J}$ Wardle Development of a general nutrition knowledge questionnaire for adults. Eur. J. Clin. Nutr. 1999; 53:298-308.

11. Statistical Package for Social Science (SPSS, version 2010).

12. Jeruszka-Bielak M, Kollajtis-Dolowy A, Santoro A, Ostan R, Berendsen AAM, Jennings A, Meunier N, Marseglia A, Caumon E, Gillings R, de Groot LCPGM, Franceschi C, Hieke $S$ and B Pietruszka Are nutrition-related knowledge and attitudes reflected in lifestyle and health among elderly people? A study across five European countries. Front. Physiol. 2018; 9:994. 


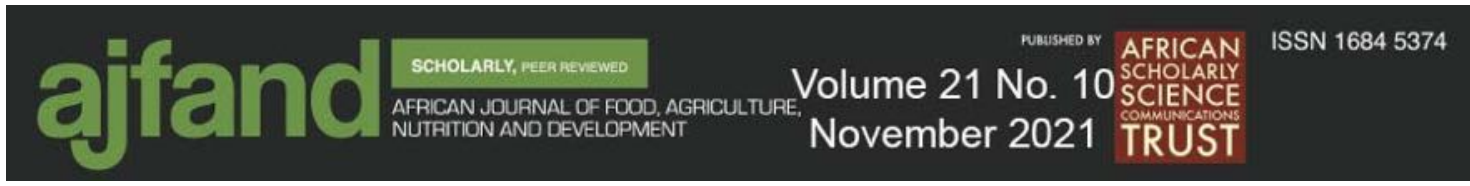

13. Obot IS The measurement of drinking patterns and alcohol problems in Nigeria. Journal of Substance Abuse 2000; 12(1):169-181.

14. Aryeetey $\mathbf{R}$ and $\mathbf{J}$ Ansong Overweight and hypertension among college of health science employees in Ghana. 2010. Retrieved from: http://www.biolin.org.br./pdf?nd11083 Accessed January 15, 2020.

15. Ziraba AK, Fotso CJ and R Ochako Overweight and obesity in urban Africa: a problem of the rich or the poor? 2010.

16. Oghagbon K, Odili V, Nwangwa $\mathbf{E}$ and $\mathbf{K}$ Pender Body mass index and blood pressure pattern of students in a Nigerian University. Int. J. Health Res 2009; 2:2-10.

17. Bakari AG, Onyemelukwe GC, Sani BG, Aliyu I S, Hassan SS and TM Aliyu Obesity, overweight and underweight in suburban northern Nigeria. Inter. $J$. Diabetes Metab. 2007; 15(2):68.

18. Fadupin GT, Adeoye A and $\mathbf{O}$ Ariyo Lifestyle and nutritional status of urban school teachers in Ibadan, Nigeria. Niger. J. Nutr. Sci. 2014; 35:1.

19. Sanusi RA, Holdbrooke JS and O Ariyo Gender differences in factors associated with overweight and obesity among civil servants in Lagos, Nigeria. Int. J. Nutr. Metab. 2015; 7(6):66-73.

20. De Vriendt T, Matthys $\mathbf{C}$, Verbeke W, Pynaert I and S De Henauw Determinants of nutrition knowledge in young and middle-aged Belgian women and the association with their dietary behaviour. Appetite 2009; 52:788-79232.

21. Bonaccio M, Di Castelnuovo A, Costanzo S, De Lucia F, Olivieri M, Donati MB, de Gaetano G, Iacoviello L and A Bonanni Nutrition knowledge is associated with higher adherence to Mediterranean diet and lower prevalence of obesity. Results from the Moli-sani study. Appetite 2013; 68:139-146.

22. Veronese N, Stubbs B, Noale M, Solmi M, Rizzoli R, Vaona A, Demurtas J, Crepaidi G and S Maggi Adherence to a Mediterranean diet is associated with lower incidence of frailty: a longitudinal cohort study. Clin. Nutr 2018; 37(5):1492-1497.

23. Shatenstein B, Gauvin L, Keller H, Richard L, Gaudreau P, Giroux F, GrayDonard K, Jabbour M, Morais JA and H Payette Baseline determinants of global diet quality in older men and women from the NuAge cohort. J. Nutr. Health Aging 2013; 17:419-425.

24. Lin $\mathbf{W}$ and $\mathbf{Y W}$ Lee Nutrition knowledge, attitudes and dietary restriction behaviour of Taiwanese elderly. Asia Pac. J. Clin. Nutr 2005; 14:221-229. 


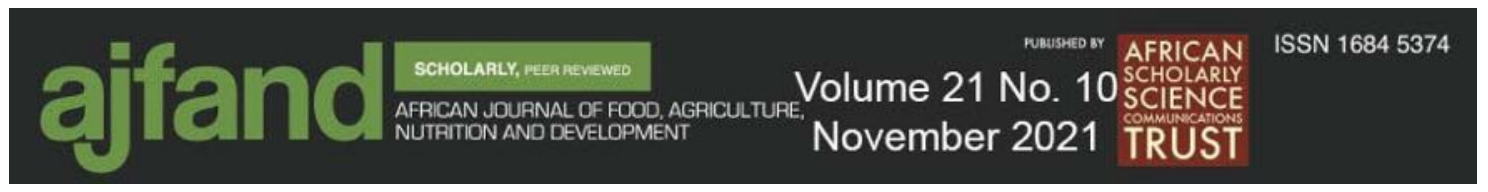

25. Parmenter $\mathbf{K}$, Waller $\mathbf{J}$ and $\mathbf{J}$ Wardle Demographic variation in nutrition knowledge in England. Health Educ. Res. 2000; 15:163-174.

26. Girois SB, Kumanyika SK, Morabia A and E Mauger A comparison of knowledge and attitudes about diet and health among 35 to 75 years-old adults in the United States and Geneva, Switzerland. Am. J. Publ. Health 2001; 91:418424.

27. Kim LP, Harrison GG and M Kagawa-Singer Perceptions of diet and physical activity among California Hmong adults and youths. Prev. Chronic. Dis. 2007; 4(4). http://www.cdc.gov/pcd/issues/2007/ oct/07 0074.htm Accessed $15^{\text {th }}$ of May, 2019.

28. Yahia N, Brown CA, Rapley $M$ and M Chung Level of nutrition knowledge and its association with fat consumption among college students. BMC Public Health 2016; 16:1047.

29. Afolabi W, Towobola S, Oguntona C and I Olayiwola Pattern of fast foods consumption and contribution to nutrient intake of Nigerian university students. Int. J. Educ. Res. 2013; 1(5):1-10.

30. Thomas LJ, Almanza B and R Ghiselli Nutrition knowledge of rural older populations: can congregate meal site participants manage their own diets? $J$. Nutr. Elder. 2010; 29: 325-344.

31. Spronk I, Kullen C, Burdon C and H O'Connor Relationship between nutrition knowledge and dietary intake. Br. J. Nutr. 2014; 28:1713-1726.

32. Polidori MC Antioxidant micronutrients in the prevention of age related diseases. J. Postgrad. Med. 2003; 49:229- 35. 